\title{
LAPAROSCOPIC HELLER'S CARDIOMYOTOMY FOR ACHALASIA CARDIA WITH AND WITHOUT DOR FUNDOPLICATION - OUR INITIAL EXPERIENCE.
}

\author{
R. Sahadev1, Preethan K.N22, G.R. Sowmya ${ }^{3}$
}

\section{HOW TO CITE THIS ARTICLE:}

R Sahadev, Preethan KN, GR Sowmya. "Laparoscopic heller's cardiomyotomy for achalasia cardia with and without dor fundoplication - our initial experience". Journal of Evolution of Medical and Dental Sciences 2013; Vol2, Issue 49, December 09; Page: 9548-9554.

ABSTRACT: BACKGROUND: Achalasia cardia is characterized by aperistalsis in the body of the esophagus coupled with inadequate relaxation of the lower esophageal sphincter, leading to the development of progressive dysphagia. Surgical treatment in the form of laparoscopic Heller's cardiomyotomy with the addition of partial fundoplication procedure like anterior Dor fundoplication is being preferred as the treatment of choice for this condition. METHODS: A retrospective case record analysis of the patients with achalasia cardia who underwent treatment in our department was performed. We found 22 cases from January 2008 to August 2013. All patients were preoperatively subjected to barium swallow examination, upper gastrointestinal endoscopy and esophageal manometry. 21 patients had undergone surgical treatment and formed the study population while one patient underwent pneumatic dilatation. The patients were followed up to a maximum period of 14 months. RESULTS: There were 10 male and 11 female patients in our study with age range between 19 years and 75 years (mean 35.14 \pm 14.80 ). Dysphagia was the main presenting symptom (100\%) followed by regurgitation of food, heartburn and chest pain. Seven patients (33.3\%) had been subjected to laparoscopic Heller's myotomy while the rest (66.7\%) underwent laparoscopic Heller's with anterior partial Dor fundoplication. There was one intraoperative small mucosal perforation which was repaired. Postoperatively all the patients had good relief from dysphagia. Two minor complications included development of gastroesophageal reflux symptoms and stickiness in the throat in one cases each. CONCLUSION: Laparoscopic myotomy is effective choice for the treatment of achalasia cardia. The use of Dor fundoplication helps to reduce symptomatic gastroesophageal reflux. Standard workup preoperatively should include barium swallow fluoroscopic examination, UGI endoscopy and esophageal manometry. Use of intraoperative endoscopy does not significantly enhance the operative times.

KEYWORDS: Achalasia Cardia, Laparoscopic Heller's Myotomy, Dor Fundoplication, Esophageal Manometry, Upper GI endoscopy, Barium Swallow

INTRODUCTION: Achalasia cardia is an uncommon benign primary disorder of esophageal motility. The reported incidence is about 1 in 100,000 persons per year. $(1,2)$ It occurs due to the impaired or absent esophageal motility in combination with a inappropriate and inadequate relaxation of the lower esophageal sphincter in response to food bolus. Though the disease is well documented and the treatment protocols established, the pathogenesis is still not clearly understood. It has been postulated to occur as a result of degeneration of the ganglia in the myentric plexus. $(3,4)$ Other acquired causes of achalasia cardia include viral infections and autoimmune pathology. $(5,6)$

Achalasia was first described by Sir Thomas Willis, who in 1672, treated a patient with such condition using a sponge on a whalebone for dilatation. (7) It was however known as cardiospasm 


\section{ORIGINAL ARTICLE}

till the term 'achalasia' was coined by Sir Arthur Hurst in 1927. (8) Ernst Heller, in 1913, described a technique to surgically treat the condition. He divided the muscular fibres of the gastroesophageal junction (GEJ) both anteriorly and posteriorly by a thoracic approach. (9) Zaaijer modified this procedure and performed only the anterior myotomy with equally good results. (10) Later there were modifications in the approach from thoracic to abdominal and recently to the minimally invasive surgery which was first demonstrated by Shimi et al in 1991. (11)

The symptoms of achalasia include dysphagia, heartburn, regurgitation, chest pain, weight loss and occasionally respiratory symptoms. (2) Primary screening for achalasia is usually by a real time fluoroscopic barium swallow examination (BE) which demonstrates a dilated and aperistaltic esophagus with narrowed lower esophageal sphincter which classically is termed as "bird beak" appearance. Esophageal manometry (EM) is the investigation of choice to confirm the presence of achalasia. It demonstrates the a peristalsis of the body along with raised lower esophageal sphincter pressure with a incomplete relaxation of the lower esophageal sphincter. (12) Upper gastrointestinal (GI) endoscopy is also used to identify the condition but its use is mainly to identify cases of pseudoachalasia due to malignancy. (2)

The technique of laparoscopic myotomy has been widely accepted as the treatment of choice for achalasia. However there are differences regarding the addition of a fundoplication and also the type of fundoplication. We have followed laparoscopic Heller's myotomy (LHM) alone in the early part of the series and later added an anterior partial Dor fundoplication (LHM+DF).

METHODS: A retrospective case record analysis of the data was performed. We found the records of 22 cases of achalasia treated at our hospital from January 2008 to August 2013. Patient demographic data, presenting symptoms, investigations done, treatment methods used and follow up data were noted and analyzed. Preoperative workup was done in all cases and included a detailed history and a clinical examination. Investigations included routine hematological and biochemical parameters. Barium swallow, upper GI endoscopy and esophageal manometry were done in all cases. High resolution esophageal manometry was done in one case.

The operative procedure followed was laparoscopic Heller's myotomy in all cases except for a patient who was medically not fit for surgery and was subsequently referred for pneumatic balloon dilatation (PD). In initial seven cases myotomy alone was performed. In the later cases Dor fundoplication was added and currently is the standard procedure in our department. The positioning was French type and we usually use five ports. Two $10 \mathrm{~mm}$ ports - one for the telescope and camera positioned supraumbilically and the other for the working port, in the left hypochondrium below the costal margin in the mid clavicular line and three $5 \mathrm{~mm}$ ports - one in the epigastrium for liver retraction, one in the right hypochondrium for working port and the last in the left lumbar region lateral and inferior to the umbilicus for stomach retraction. Myotomy was done starting at or above the gastroesophageal junction and was extended cranially for $4-5 \mathrm{cms}$ in initial cases and later was standardized to $6-7 \mathrm{cms}$. Caudally the incision was extended onto the stomach side for a length of about $1-1.5 \mathrm{cms}$ and finally a Dor fundoplication is performed.

Intraoperative upper GI endoscopy was used in all cases to identify the level of the narrowing. It also helps in testing for any mucosal tears intraoperatively. No nasogastric tube was left in situ postoperatively. Oral feeds were initiated by $24 \mathrm{hrs}$ and gradually solid foods were introduced. The patients were usually discharged on $3^{\text {rd }}$ or $4^{\text {th }}$ post operative day. All cases were 


\section{ORIGINAL ARTICLE}

subjected to a repeat barium swallow examination and upper GI endoscopy at 2 weeks after surgery and results were noted. Results were also enquired from the patients especially with regard to relief of dysphagia.

RESULTS: Twenty two patients were screened initially in the study. 21 patients were subjected to surgical treatment while one patient was referred for pneumatic balloon dilatation and hence removed from the study. The age range was between 19 years and 75 years with a mean age of 35.14 years. The gender distribution was 10 males and 11 females with the M:F ratio being almost equal. The duration of the symptoms in the patients varied from 2 months to 15 years with a mean of 27.4 months. The commonest symptoms included dysphagia in all cases followed by regurgitation in 10 cases $(47.6 \%)$, chest pain and heartburn in $28.6 \%$ each. One patient had severe respiratory illness which precluded surgery and hence was not operated. Two of the patients $(9.52 \%)$ had undergone pneumatic balloon dilatation earlier, one of which had undergone the procedure twice.

Barium swallow fluoroscopy and UGI endoscopy was done in all cases before surgery. Esophageal manometry was also obtained. Barium examination showed dilated esophageal body and bird beak appearance in $95.23 \%$ of cases. One patient had sigmoid esophagus and was reported on chest x-ray as doubtful mediastinal mass. Subsequent CT scan obtained, clearly demonstrated megaesophagus. UGI endoscopy demonstrated dilated esophagus in all cases with food stasis. Two patients $(9.52 \%)$ had signs of esophagitis on endoscopy. Esophageal manometry done in all cases showed raised resting pressure of LES and a peristalsis of the esophageal body.

The operating time was almost similar in cases which underwent LHM alone when compared to the LHM with addition of DF. The range was between 90-150 mins (mean 122.14) in patients undergoing myotomy alone while it was in the range of 90-170 mins (mean 126.79) with addition of DF. The blood loss during the surgery was negligible and none of the patients required blood transfusions.

Mucosal tear was noticed in one case (5.26\%) and was repaired intraoperatively by using 30 polyglactin sutures. This patient had a Dor fundoplication as a cover for the suture line. One patient (14.28\%) developed gastroesophageal reflux symptoms in the postoperative follow-up period and was managed conservatively with medications. The patient had undergone LHM only later improved with counseling and awareness regarding the life style modifications. One patient (7.14\%) complained of sensation of stickiness in the throat following LHM+DF. UGI endoscopy and barium examinations demonstrated a good myotomy with no resistance to the passage of bolus or the endoscope. On enquiring the patient revealed the fact that he was reluctant to use solid food in his diet as he still feared dysphagia. He was counseled and solid food was gradually introduced in his diet. Subsequently he responded and currently is symptom free.

Duration of stay postoperatively varied from 3-10 days with a mean of 4.1 days. All the patients were followed up for a varying period of time after discharge (range 3 months to 14 months). All the patients were subjected to barium swallow examination and upper GI endoscopy at two weeks and at three months after the surgery. Both demonstrated a good myotomy with no resistance to the passage of bolus or the endoscope. A significant number of patients were lost during follow-up and hence a long term follow-up was not possible. None of the patients had persistent GER symptoms or dysphagia. 


\section{ORIGINAL ARTICLE}

DISCUSSION: Achalasia cardia is essentially diagnosed by the use of barium swallow, upper GI endoscopy and esophageal manometry. Barium swallow and manometry effectively diagnosed 95\% and $100 \%$ of cases in our study. Upper GI endoscopy has been primarily used to identify pseudoachalasia. (13)

The primary goal in the treatment of achalasia cardia is the alleviation of symptoms mainly dysphagia. Dysphagia was seen in $100 \%$ of our cases and the relief obtained was also similar. Various modes of treatments have been utilized to achieve the primary goal, like the use of pharmacotherapeutic drugs, pneumatic balloon dilatation, botulinum toxin injection and surgery. Myotomy was initially performed through the thoracic route and later evolved through the abdominal route in the form of laparotomy. (14) Since the advent of laparoscopic surgery, laparoscopic myotomy has been the preferred choice with its good results and the added advantages of minimally invasive surgery. The outcomes of these various surgical approaches have been recorded by previous studies to be $83 \%$ for thoracic approach, $85 \%$ for abdominal approach and $89 \%$ for laparoscopic approach. (15) In our study we have seen $91.48 \%$ improvement in immediate outcome. However longer follow-up is required. Likewise the appearance of GER symptoms have also been further reduced by the laparoscopic myotomy combined with fundoplication to less than $9 \%$ as compared to $31 \%$ of abdominal myotomy. (15) Our study suggests a similar reduction in GER symptoms postoperatively.

Various authors have used myotomy of varying lengths in their series. Myotomy alone disrupts the LES and thereby makes the esophagus vulnerable for acid reflux injury. A short myotomy may not relieve the symptoms effectively while a longer myotomy on the stomach predisposes to acid reflux into esophagus. This can be reduced effectively by the use of fundoplication. There has been many studies regarding the use of Dor or Toupet fundoplication and have reported equally good results. $(16,17,18)$ However we have been using the Dor fundoplication in our hospital.

Intraoperative endoscopy allows the visualization of the point of narrowing and thus helps in placing of the myotomy. In addition any tears in the mucosal tube of the esophagus or also on the stomach are easily identified. (19) Mucosal perforation during myotomy might be seen more in patients who have previously undergone other forms of treatment like PD or BT injection for achalasia as a result of scarring and obliteration of the submucosal layer. $(19,20)$ We have been using the intraoperative endoscopy routinely in all cases of achalasia and has helped us to identify a small mucosal tear in one of our cases which was repaired. In our view intraoperative endoscopy can be performed easily and does not prolong the operating time significantly. The mean operating time was similar in both the groups of patients. The similarity between the two may be due to the learning curve effect in the initial cases.

In conclusion, laparoscopic surgery is a safe and effective choice for the treatment of achalasia cardia. The use of Dor fundoplication helps to reduce symptomatic GER. Standard workup preoperatively should include barium swallow fluoroscopic examination, UGI endoscopy and esophageal manometry. Use of intraoperative endoscopy does not significantly enhance the operative times. 


\section{ORIGINAL ARTICLE}

\section{REFERENCES:}

1. Howard PJ, Maher L, Pryde A, Cameron EWJ, Heading RC. Five year prospective study of the incidence, clinical features, and diagnosis of achalasia in Edinburgh. Gut.1992;33:1011-1015.

2. Richter JE. Achalasia - An Update. J Neurogastroenterol Motil.2010 July; 16(3):232-242.

3. Ghoshal UC, Daschakraborty SB, Singh R. Pathogenesis of achalasia cardia. World J Gastroenterol. 2012 June;18(24):3050-3057.

4. Goldblum JR, Whyte RI, Orringerb MB, Appelman HD. Achalasia, a morphologic study of 42 resected specimens. Am J Surg Path.1994;18:327-337.

5. Katilius M, Velanovich V. Heller Myotomy for Achalasia: Quality of Life Comparison of Laparoscopic and Open Approaches. Journal of the Society of Laparoendoscopic Surgeons.2001;5:227-231.

6. Facco M, Brun P, Baesso I, Costantini M, Rizzetto C, Berto A, Baldan N, Palu G, Semenzato G, Castagliuolo I, Zanitto G. T cells in the myentric plexus of achalasia patients show a skewed TCR repertoire and react to HSV-1 antigens. Am J Gastroenterol. 2008;103:1598-1609.

7. Willis T. Pharmaceutice Rationalis Sive Diatribe de Medicamentorum Operationibus in Human Corpore. London, England:Hagae Comitis;1674.

8. Hurst AF. Treatment of achalasia of the cardia: so-called "cardiospasm". Lancet. 1927;209:618619.

9. Heller E. Extramucose Cardioplastie beim Chronischen Cardiospasmus mit Dilatation des Oesophagus. Mitt Grenzeg Med Chir. 1913;2:141-149.

10. ZaaijerJH. Cardiospasm in the aged. Ann Surg. 1923;77(5):615-617.

11. Shimi S, Nathanson LK, Cuschieri A. Laparoscopic cardiomyotomy for achalasia. J R Coll Surg Edinb. 1991 June;36(3):152-154.

12. Hirano I, Tatum RP, Shi G, Sang Q, Joehl RJ, Kahrilas PJ. Manometric heterogenecity in patients with idiopathic achalasia. Gastroenterology. 2001;120:789-798.

13. Muller M, Eckardt AJ, Wehrmann T. Endoscopic approach to achalasia. World J Gastrointest Endosc 2013 August 16; 5(8): 379-390.

14. Vaezi MF, Pandolfino JE, Vela MF. ACG Clinical Guideline: Diagnosis and Management of Achalasia. Am J Gastroenterol. 2013.108(8):1238.

15. Campos GM, Vittinghoff E, Rabl C, Takata M, Gadenstatter M, Lin F, Ciovica R. Endoscopic and surgical treatments for achalasia: A systematic review and meta-analysis. Ann Surg. 2009;249(1):45-57.

16. Torquati A, Richards WO, Holzman MD, Sharp KW. Laparoscopic Myotomy for Achalasia Predictors of Successful Outcome After 200 Cases. Annals of Surgery.2006 May;243(5):587593.

17. Oelschlager BK, Chang L, Pellegrini CA. Improved outcome after extended gastric myotomy for achalasia. Arch Surg.2003;138:490-495; discussion 495-497.

18. Richards WO, Torquati A, Holzman MD, Khaitan L, Byrne D, Lutfi R, Sharp KW. Heller myotomy versus Heller myotomy with Dor fundoplication for achalasia: a prospective randomized double-blind clinical trial. Ann Surg. 2004 Sep;240(3):405-12; discussion 412-5.

19. Patti MG, Molena D, Fisichella PM, Whang K, Yamada H, Perretta S, Way LW. Laparoscopic Heller myotomy and Dor fundoplication for achalasia: analysis of successes and failures. Arch Surg.2001 Aug;136(8):870-7. 


\section{ORIGINAL ARTICLE}

20. Spiess AE, Kahrilas PJ. Treating achalasia: from whalebone to laparoscope. JAMA. 1998 Aug 19;280(7):638-42.

\section{FIGURES:}

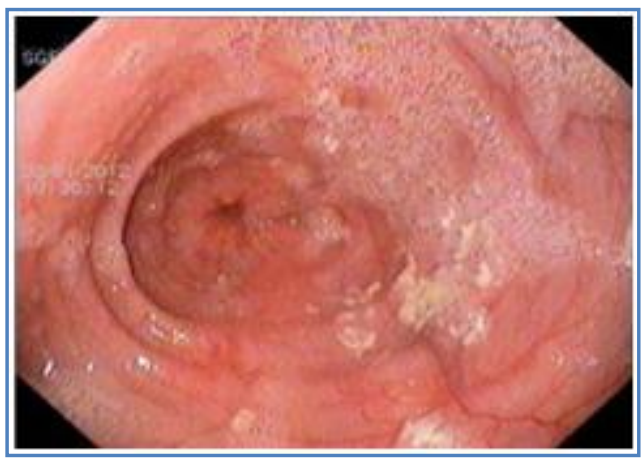

Fig 1a: Dilated esophagus in achalasia

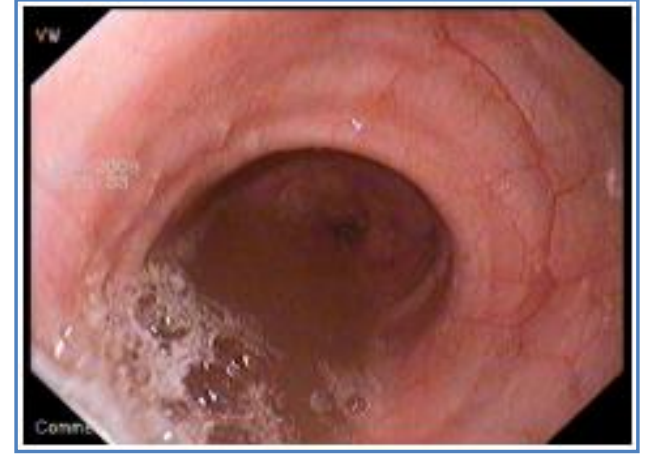

Fig 1b: Stasis in esophagus in achalasia

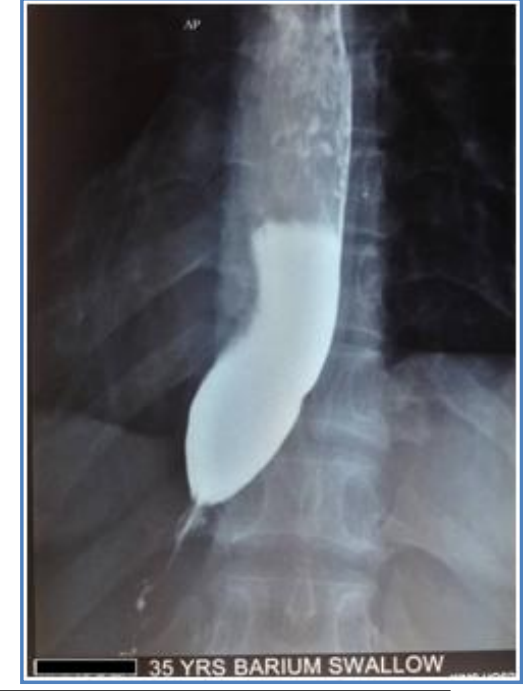

Fig 2: Ba swallow - preop

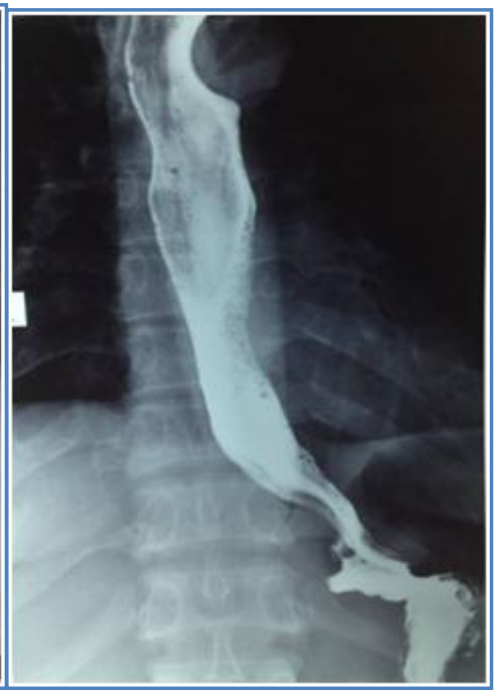

Fig 3: Barium swallow - postop

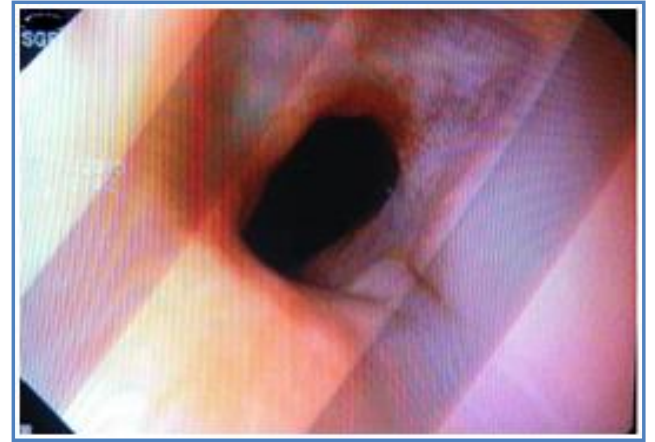

Fig 4: Intraoperative endoscopy after myotomy

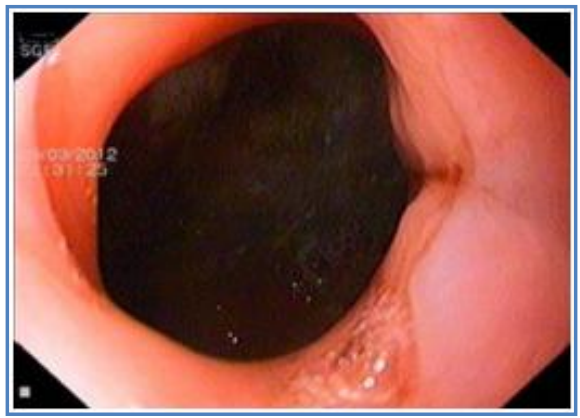

Fig 5: EGD showing GEJ on follow-up 


\section{ORIGINAL ARTICLE}

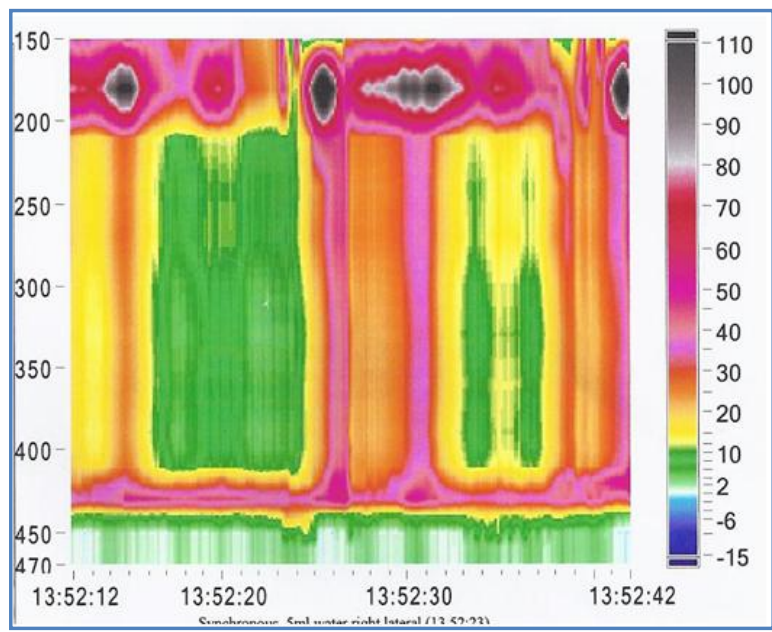

Fig 6: Esophageal Manometry demonstrating absent esophageal peristalsis and absent LES relaxation preoperatively.

\section{AUTHORS:}

1. R. Sahadev

2. Preethan K.N.

3. G.R. Sowmya

\section{PARTICULARS OF CONTRIBUTORS:}

1. Associate Professor, Department of Surgical Gastroenterology, Kempegowda Institute of Medical Sciences, Bangalore.

2. Assistant Professor, Department of Surgical Gastroenterology, Kempegowda Institute of Medical Sciences, Bangalore.

3. Senior Resident, Department of Surgical Gastroenterology, Kempegowda Institute of Medical Sciences, Bangalore.

\section{NAME ADRRESS EMAIL ID OF THE CORRESPONDING AUTHOR:}

Dr. R. Sahadev, Associate Professor, Department of Surgical Gastroenterology, Kempegowda Institute of Medical Sciences Hospital and Research Centre, K.R. Road, V.V. Puram, Bangalore - 560004 .

Email - sahadev2002@gmail.com

Date of Submission: 22/11/2013. Date of Peer Review: 23/11/2013. Date of Acceptance: 28/11/2013. Date of Publishing: 03/12/2013 